\title{
Monitoring a Massive Escape of European Sea Bass (Dicentrarchus Labrax) at an Oceanic Island: Potential Species Establishment
}

\section{Besay Ramírez $^{1 *}$, Leonor Ortega ${ }^{1,2}$, Daniel Montero ${ }^{3}$, Fernando Tuya ${ }^{1}$ and Ricardo Haroun ${ }^{1}$}

${ }^{1}$ Research Group on Biodiversity and Conservation, Center for Biodiversity and Environmental Management, University of Las Palmas de Gran Canaria, Las Palmas 35017, Spain

${ }^{2}$ Philippe Cousteau "Union of the Ocean" Foundation, C/ General Oraá 26, 28006 Madrid, Spain

${ }^{3}$ Aquaculture Research Group, University of Las Palmas de Gran Canaria, P.O. Box 56, 35200 Telde, Spain

\begin{abstract}
The post-escape behavior of aquaculture escapees is a growing topic of research. We monitored a massive escape event of the European sea bass, Dicentrarchus labrax, which occurred at a sea-cage fish farm off the oceanic island of La Palma, Canary Islands, eastern Atlantic. Stomach contents and gonadal development of escapees were analyzed from two islands (Gran Canaria and La Palma) in order to assess the degree of postescape establishment,. We also tested (at both islands), the suitability of fatty acid profiles as biomarkers of aquaculture escapes, processing recaptured escaped fish at a range of distances away from aquaculture facilities. Escaped European sea bass concentrated within breakwaters and decreased in abundance through time after the massive escape at La Palma. Decapod crustaceans (particularly Percnon gibbesi and Rhynchocinetes $s p$ ) were the main diet constituents of escapees, followed by fishes (mainly the parrotfish, Sparisoma cretense). Only one spawner male was found. Crude lipid, oleic acid, linoleic acid, linolenic acid, eicosapentaenoic acid, $\sum$ n-9 fatty acids and $\sum$ monounsatured fatty acids showed higher values in cultured or escaped individuals near cages relative to fish far away from farms. Arachidonic acid, docosahexaenoic acid, $\sum n-3$, satured fatty acids, $\sum n-3 / \sum n-6$ ratio and Palmitic acid showed the opposite pattern. Our data showed that escaped European sea bass is able to exploit natural recourses, altering their fatty acid profiles relative to farmed conspecifics. The usefulness of fatty acids as biomarkers is, however, limited to a short period of time after escape events.
\end{abstract}

Keywords: Escapees; Stomach contents; Fatty acids; Gonadal development; Canary islands

\section{Introduction}

Among environmental issues facing aquaculture, escapes are widely regarded as a major problem in the marine environment, including genetic interactions through inbreeding, transfer of pathogens, prey predation, introduction of alien species, habitat alteration, etc. [1-8]. The European sea bass, Dicentrarchus labrax, is a voracious predator, feeding mainly on crustaceans, molluscs and fishes [9-13], and its diet changes with fish size [13-15] for escaped individuals, the diet also depends on the time at liberty [13].

Escapes at some locations may be particularly problematic, principally where local populations are reduced, or in areas outside the species' natural distribution range [7]. Current populations of the European sea bass in studied islands (Gran Canaria and La Palma) (Figure 1) are related to aquaculture escapes because no native populations had existed $[12,16]$. In these islands, for example, escaped European sea bass diet overlaps with other top predators and may become a new competitor for local species $[12,13,17]$. Yet, there is no reported evidence of reproduction of escaped European sea bass from studied islands [12,17], although developed gonads have been found [12].

Several morphological and physiological indicators have been proposed as useful tools for the identification of escapees, in which the FA profile has been claimed to be a good bio-indicator [18-20]. The FA profile has received increasing attention due to changes in aqua feed ingredients over recent years. Traditionally, fish were fed with diets based on fishmeal and fish oil as the main ingredients to ensure a competitive price and adequate content in some essential FAs for fish, such as docosahexaenoic acid (DHA) (22:6n-3), eicosapentaenoic acid (EPA) (20:5n-3) and arachidonic acid (ARA) (20:4n-6). These FAs, which have a plethora of very important functions, are considered essential for marine fish, since these species do not have the ability to bio-convert shorter FAs into these FAs [21]. Given that the world production of fish oil is stagnated with the consequent increase in cost, there is a strong trend for the use of vegetable oils as fish oils substitutes [22]. These FAs precursors are incorporated into the tissues of farmed fish, and can also be transferred to wild fish [23]. Wild fishes around offshore aquaculture cages may feed on pellets released from farms, resulting in changes in body condition and FA profiles, bringing their body composition and that of other organisms in different trophic levels closer to that of cultivated fish [23-25]. For this reason, the presence of certain FAs, such as LA, ARA and oleic acid (OA) (18: 1n-9), in wild organisms has been proposed as an indicator of the influence of aquaculture on marine ecosystems [23,25-27].

The goal of this paper was, firstly, to analyze the spatio-temporal variability in the population structure of escaped European sea bass after a massive escape (approximately 1,500,000 fish, 400,000 kg, $30-45 \mathrm{~cm}$ of total length at the moment of escape) that occurred on February 2010 at La Palma Island (Canary Islands, eastern Atlantic)

*Corresponding author: Besay Ramírez, Research Group on Biodiversity and Conservation, Center for Biodiversity and Environmental Management, University of Las Palmas de Gran Canaria, Las Palmas 35017, Spain, Tel: +34-928-132-900; E-mail: besay.ramirez@gmail.com

Received February 19, 2015; Accepted April 20, 2015; Published May 15, 2015

Citation: Ramírez B, Ortega L, Montero D, Tuya F, Haroun R (2015) Monitoring a Massive Escape of European Sea Bass (Dicentrarchus Labrax) at an Oceanic Island: Potential Species Establishment. J Aquac Res Development 6: 339 doi:10.4172/2155-9546.1000339

Copyright: ( 2015 Ramírez B, et al. This is an open-access article distributed under the terms of the Creative Commons Attribution License, which permits unrestricted use, distribution, and reproduction in any medium, provided the original author and source are credited. 


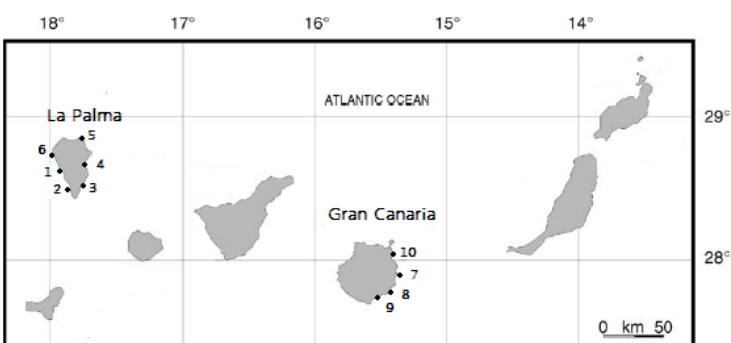

Figure 1: Map of the study area detailing sampling localions at La Palma Island: 1 Tazacorte (Acuipalma S.L. farm); 2 El Remo (marine reserve); 3 La Salemera; 4 Santa Cruz de la Palma; 5 Puerto Talavera; 6 Puntagorda; and Gran Canaria Island: 7 Melenara (ADSA S.L. and Canexmar S.L. farms); 8Arinaga; 9 Castillo del Romeral (ADSA S.L. and Playa Vargas S.L. farms); 10 (San Cristobal).

(Figure 1). We secondly determined whether escaped European sea bass diet, reproductive potential and FA profile changed with distance from aquaculture cages. We hypothesize that: (1) escaped fish can redistribute around the entire island perimeter after a massive escape, (2) being able to adapt to the wild by consuming local prey, (3) lacking reproduction and (4) altering their FA profiles depending on distance from the source of escapees.

\section{Materials and Methods}

\section{Sampling design and study locations}

To monitor the massive escape of European sea bass that occurred between the 20 and $26^{\text {th }}$ February 2010 at La Palma Island, we selected six locations throughout the entire island perimeter (Figure 1). One location was immediately adjacent to the escape point (a sea-cage fish farm off Tazacorte, Figure 1) and the rest were selected at different distances away from this point, northward and southward around the entire island perimeter. One location (El Remo) was set within a marine reserve (Reserva Marina Isla de La Palma). No location was selected in the north face of the island due to prevailing swells from the NW that impedes regular sampling. This protocol was repeated six times (i.e. sampling campaigns): August 2010, September 2010, October 2010, November 2010, August 2011 and October 2011. Locations encompassed a range of habitats at shallow water (ca. 5-10 m depth).

To study stomach contents, gonad development and FAs profile, escaped European sea bass were captured by spear-fishing throughout the entire study, i.e. from August 2010 to October 2011, at both La Palma and Gran Canaria. Although some of them presented unusable tissues due to shaft impacts, this was the most appropriate and effective capture method because local fishermen do not fish close to the surf, where European sea bass are often grouped [12]. Catches were kept in ice until processed in the laboratory, where individuals were weighed (accuracy to $0.1 \mathrm{~g}$ ) and measured (accuracy to $0.1 \mathrm{~cm}$ ). The gonads, stomachs, muscle tissue and livers were removed from each individual; the gonads were preserved in formaldehyde and the stomachs preserved in $70 \%$ ethanol; muscle tissue and livers were frozen for subsequent lipid analysis. Samples for lipid analyses were categorized according to 3 distances from aquaculture facilities: 'Cages': $0 \mathrm{~km}$ (inside cages), 'Near cages': $<10 \mathrm{~km}$ and 'Far away from cages': $>10 \mathrm{~km}$. In addition to samples collected at La Palma Island (i.e. where the escape event took place), samples were simultaneously taken at Gran Canaria Island (Figure 1) to assess whether patterns with distance from aquaculture cages for a range of descriptors (see below) were consistent between the two islands. By increasing the spatial replication, the robustness of the study is enhanced if results were consistent between both islands. In La Palma Island, there is only one off-shore farm, while at Gran Canaria there are four off-shore fish farms located at two locations (Figure 1).

\section{Fish surveys}

At each location and time, fish were counted by means of visual census techniques through four replicated $50 \mathrm{~m}$ long transects, which were haphazardly laid out during daylight hours. The abundance and size of fish was recorded on waterproof paper by a SCUBA diver within $2 \mathrm{~m}$ of either side of transects, according to standard procedures implemented in the study region [28]. We also recorded the type of habitat under each transect (\%), which was categorized according to 'big boulders' ( $>2 \mathrm{~m}$ of diameter), 'small boulders' ( $<1 \mathrm{~m}$ of diameter), 'sand', 'breakwaters' (i.e. artificial man-made constructions) and 'bare rock' [28].

\section{Stomach contents}

To analyze the diet composition of escapees, stomachs were weighed and the content removed. Total food items from each stomach were placed on filter paper to eliminate excess moisture and subsequently weighed. Prey items were identified to the lowest possible taxonomic level; the total number of prey items were counted and weighed for each stomach. The percentage composition by number and weight was then calculated for each prey category to calculate the indices of importance by number (IN), wet mass (IW) and global importance (IG).

$$
\begin{aligned}
& \mathrm{IN}=[(\% \text { composition by number }) X(\% \text { occurrence })]^{1 / 2} \\
& \mathrm{IW}=[(\% \text { wet mass }) X(\% \text { occurrence })]^{1 / 2} \\
& \mathrm{IG}=(I N \%+I \mathrm{~W} \%) / 2
\end{aligned}
$$

\section{Gonadal development}

For each fish, gonads were macroscopically examined for sex differentiation to establish the stage of gonadal development, by using a visual scale of five stages of maturity based on color and the relative size of gonads: I undeveloped; II developing; III mature; IV spawn; V post-spawn [29].

\section{Lipid and FA profiles}

A total of 60 livers and 60 muscles samples were analyzed. 10 for each distance ('Cages', 'Near Cages', and 'Far away from Cages') from both La Palma and Gran Canaria islands $(n=10)$. Biochemical assays followed standard procedures [30]. Moisture content was determined by drying the sample at $105^{\circ} \mathrm{C}$, until achieving a constant weight. Crude lipid content was extracted following the method of Folch et al. [31]. FAs from total lipids (stored under nitrogen atmosphere at $-80^{\circ} \mathrm{C}$ ) were prepared by transmethylation, as described by Christie [32] and FA methyl esters separated by gas chromatography following Izquierdo et al. [33]. All analyses were conducted in triplicate.

\section{Data analysis}

Fish survey data and FA profile composition were analyzed by means of ANOVA [34]. We tested for differences in escapees abundance between locations at varying distances from the escape point around La Palma Island and the sampling times through a 2-way ANOVA that incorporated the factors: (1) "Locality" (fixed factor with six levels, corresponding to the 6 locations) and (2) "Time" (fixed factor with six levels and orthogonal to the previous factor); "Time" was considered fixed, as sampling dates were equidistantly separated. 
A $\chi^{2}$ tested for differences in diet composition (by considering the percentages of the different prey items) between islands, and a WaldWolfowitz test contrasted differences in fish length between islands. To test for differences in FA profile composition (total lipid, OA, LA, ALA, palmitic acid (PA) (16:0), ARA, EPA, DHA, $\sum$ satured, $\sum$ monounsatured, $\sum \mathrm{n}-9, \sum \mathrm{n}-6, \sum \mathrm{n}-3 \mathrm{~F}$ and $\sum \mathrm{n}-3 / \sum \mathrm{n}-6$ ratio) with varying distance from cages, 2-way ANOVAs incorporated the factors: (1) "Island" (fixed factor with two levels: La Palma and Gran Canaria); (2) "Distance" (fixed factor with three levels corresponding to the three distances from the aquaculture sea farms: 'Cages', 'Near cages' and 'Far away from cages'. Before the analyses, the Cochran's test was used to check for homogeneity of variances. If the test detected heterogeneous variances (Cochran's test, $P<0.01$ ), data transformation was performed. In some cases, variances remained heterogeneous despite transformations; the significance level was then set at the more conservative 0.01 value instead of the conventional 0.05 level to decrease a type I error [34]. If ANOVA detected significant differences, further analyses were performed by using the SNK $a$ posteriori multiple comparison test [34]. When data did not achieve homogeneous variances, the GamesHowell post hoc test was used. The SIMPER analysis identified the main contributors to differences in FA profiles between islands at varying distance from cages. A Chi square $\left(X^{2}\right)$ tested for departures from a 1:1 sex ratio. Non-metric multidimensional scaling (MDS) ordination plots were implemented to visualize differences in the FA profiles (OA, LA, ALA, PA, ARA, EPA, DHA, $\Sigma$ satured, $\sum$ monounsatured, $\Sigma \mathrm{n}-9, \Sigma \mathrm{n}$ 6, $\sum$ n-3 FAs and $\sum$ n-3/ n-6 ratio) from muscle and liver tissue between islands and the three distances from the aquaculture sea farms: 'Cages', 'Near cages' and 'Far away from cages'. The SPSS (v. 15.0), PRIMER (v. 5.2.4) and PERMANOVA (v.1.6) software were used in these statistical analyses.

\section{Results}

\section{Spatial-temporal distribution of escaped European sea bass after the escape event}

The mean abundance of escaped European sea bass at La Palma Island was $4.9 \pm 14.3$ ind $100 \mathrm{~m}^{-2}$ (mean $\pm \mathrm{SE}, n=144$ transects) during the study period, which varied between 0 fish in several transects to a maximum of 100 ind $100 \mathrm{~m}^{-2}$. All locations had escaped European sea bass, at least one individual during the study period (Appendix 1). The ANOVA demonstrated that escaped European sea bass densities decreased significantly $(\mathrm{p}<0.01)$ through the study period, particularly in October 2010 (Figure 2 and Table 1) and that Tazacorte (i.e. the point of massive release) had significantly $(\mathrm{p}<0.01)$ higher densities $\left(17.0 \pm 29.1\right.$ ind $\left.100 \mathrm{~m}^{-2}\right)$ than the other locations (Figure 2). The largest densities of escaped European sea bass from La Palma were observed in breakwaters (Game-Howell test, $\mathrm{p}<0.05$, Figure 3). The length range of observed European sea bass varied between 15 and $60 \mathrm{~cm}$ (Figure 4); the majority of fish, however, were between 35 and $50 \mathrm{~cm}$ (Appendix 1).

\section{Stomach contents of escaped European sea bass}

A total of 101 individuals were collected (Appendix 2); a total of 77 stomachs were analysed (24 stomachs were broken by the spear impact during field collections); twenty stomachs (25.97\%) were empty and 19 stomachs (24.67\%) contained unidentifiable items. Decapod crustaceans were the main prey, followed by osteichthyes and inorganic matter (Figure 5). The most commonly preyed crustaceans were Percnon gibbesi and Rhynchocinetes $s p$, while the main fish species was the parrotfish, Sparisoma cretense (Figure 5). Stomachs from La Palma $(\mathrm{n}=54)$ mainly contained crustaceans, while stomachs from Gran Canaria $(n=20)$ were dominated by unknown osteichthyes. This

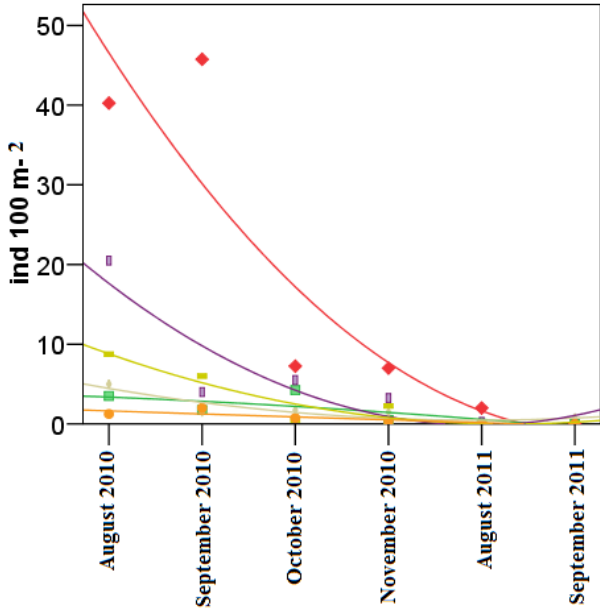

Figure 2: Mean abundances (ind $100 \mathrm{~m}^{-2}$ ) of escaped sea bass, Dicentrarchus labrax, at each time and location at La Palma Island. 1 Tazacorte (Acuipalma S.L. farm); 2 El Remo (marine reserve); 3 La Salemera; 4 Santa Cruz de la Palma; 5 Puerto Talavera; 6 Puntagorda.

\begin{tabular}{|c|c|c|c|c|}
\hline Source of variation & df & MS & F & P \\
\hline Time & 5 & 204.909 & 79.096 & 0.0002 \\
\hline Locality & 5 & 150.132 & 57.951 & 0.0004 \\
\hline Time x Locality & 25 & 29.859 & 11.526 & 0.2918 \\
\hline Residual & 108 & 25.907 & & \\
\hline
\end{tabular}

Table 1: ANOVA results of the effect of 'Time' and 'Locality' on the mean abundance of sea bass (Dicentrarchus labrax) at La Palma Island.

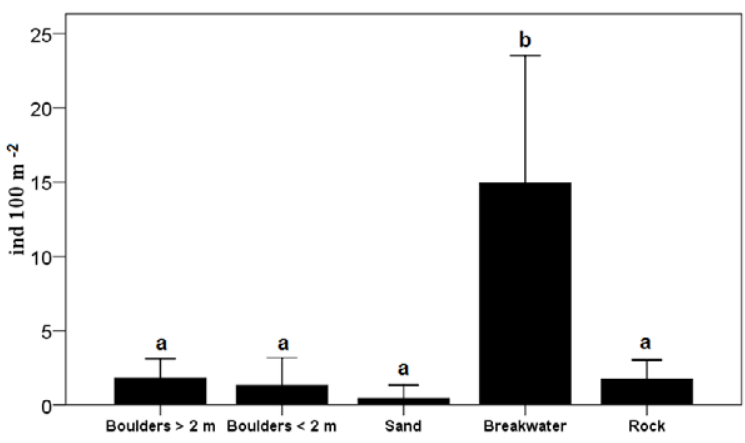

Figure 3: Mean abundances (ind $100 \mathrm{~m}^{-2}$ ) of escaped sea bass, Dicentrarchus labrax, at different substratum types at La Palma Island (data pooled from the different locations). Alphabetic superscripts indicate significant differences.

resulted in significant differences in diet between La Palma and Gran Canaria $\left(\chi^{2}=100.2421\right.$, d.f. $\left.=16, p<0.0001\right)$, despite a lack of significant differences in fish length between islands $\left(Z_{\text {adjusted }}=-2.5266, p=0.8407\right)$. However, similar percentages of Sparisoma cretense and inorganic matter (sand and plastics) were presented in fish stomachs from both islands.

\section{Gonadal development of escaped European sea bass}

A total of 87 escaped European sea bass were examined; gonads from 14 individuals were not analyzed due to spear impact during collection. The sex ratio did not deviate from a theoretical 1:1 ratio $\left(\chi^{2}\right.$ 
Citation: Ramírez B, Ortega L, Montero D, Tuya F, Haroun R (2015) Monitoring a Massive Escape of European Sea Bass (Dicentrarchus Labrax) at an Oceanic Island: Potential Species Establishment. J Aquac Res Development 6: 339. doi:10.4172/2155-9546.1000339

Page 4 of 9

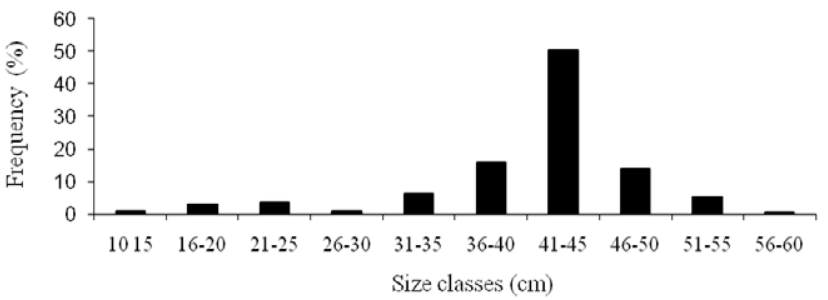

Figure 4: Size-frequency distributions of sea bass, Dicentrarchus labrax, escaped in La Palma on February 2010 (data pooled from the different locations).

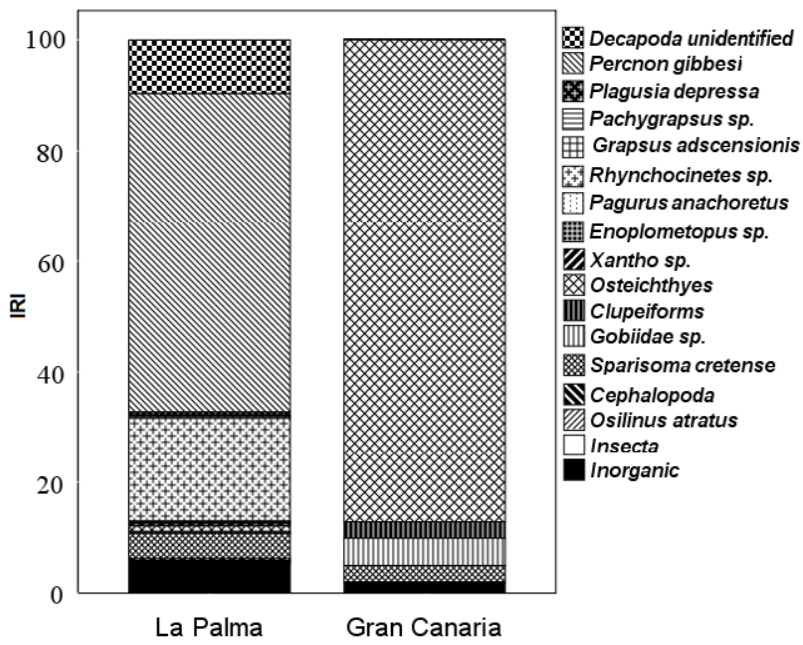

Figure 5: Percentage Index of Relative Importance (\% IRI) of different prey in the diet of sea bass, Dicentrarchus labrax, escaped from La Palma and Gran Canaria islands.

$=2.400$, d.f. $=1, \mathrm{p}=0.121)$. About $20.7 \%$ of escaped European sea bass were sexually undefined. The $87.5 \%$ of males and $91.7 \%$ of females presented immature gonads (stages I and II); only $8.3 \%$ (considering both males and females) were mature (stage III) and exclusively 1 male were in a spawning state (state IV). No females were found in the IV stage. No fish (both male and female) were found in stage V.

\section{FA profiles of escaped European sea bass}

For Gran Canaria Island, the nMDS plot did not show a separation of individuals according to distance from cages for both muscle and liver tissues (Figure 6a and 6b). In contrast, at La Palma Island, individuals separated according to their distance from cages (Figure 6a and 6b). This resulted in an inconsistent pattern in FA profiles among groups at varying distance from cages between islands (MANOVA, significant 'Island $x$ Distance' interaction, Table 2). The SIMPER analysis showed that, for muscle tissue, the main differentiating variables between localities at varying distance from the cages were: total lipid, DHA, LA, Ssatured, $\Sigma$ monounsatured and $\Sigma$ n-3 FAs. For liver tissue, the main contributors to dissimilarities were total lipid, DHA, OA, ¿satured, Emonounsatured and En-3 FAs.

The majority of FAs showed a similar pattern with varying distance
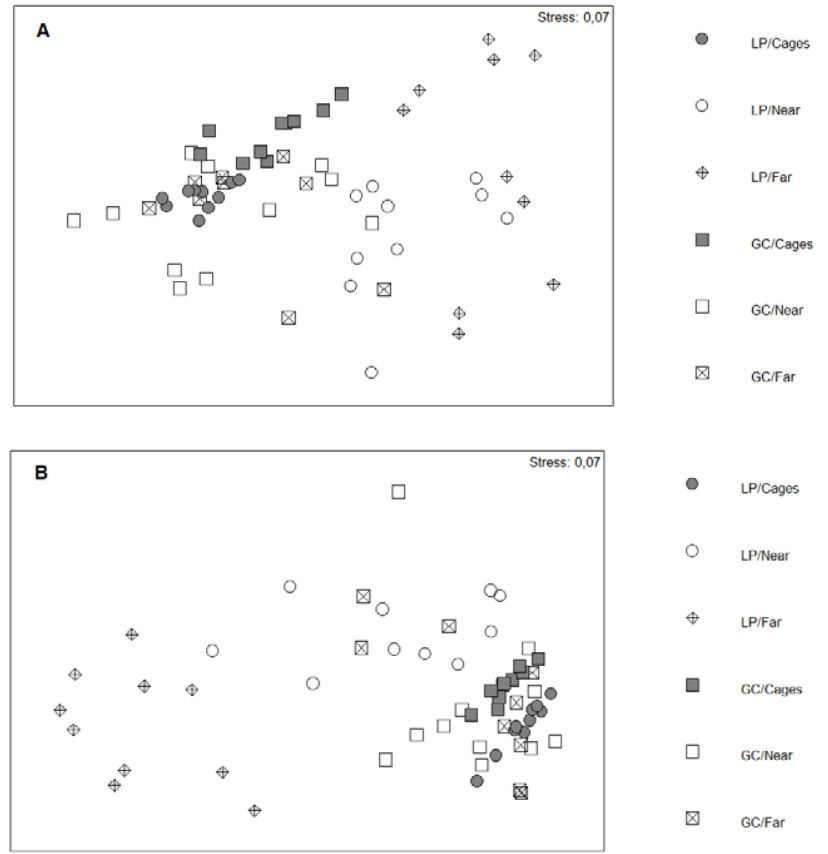

Figure 6: Non-metric multi-dimensional scaling ordination of $(A)$ muscle and (B) liver fatty acids profiles of sea bass, Dicentrarchuslabrax,from 'Cages', 'Near' ( $<10 \mathrm{~km}$ away from the cages) and 'Far' ( $>10 \mathrm{~km}$ away from the cages) at La Palma (LP) and Gran Canaria (GC) islands.

\begin{tabular}{|c|c|c|c|c|c|}
\hline $\begin{array}{c}\text { Source of } \\
\text { variation }\end{array}$ & df & MS & $\mathbf{F}$ & $\mathbf{P}$ & Pairwise tests \\
\hline Island (Is) & 1 & 6.875 .190 & 220.042 & 0.0002 & \\
\hline Distance (D) & 2 & 5.596 .024 & 179.102 & 0.0002 & \\
\hline Is x D & 2 & 5.857 .735 & 187.478 & 0.0002 & $\begin{array}{c}\text { LP: 'Cages' * 'Near' * 'far away' } \\
\text { GC: 'Cages' = 'Near' = 'far away' }\end{array}$ \\
\hline Residual & 54 & 312.450 & & & \\
\hline
\end{tabular}

Table 2: Result of multivariate analysis of variance (MANOVA) testing for differences in the fatty acids profiles (including liver and muscle tissue) between island and varying distance from farms. LP: La Palma, GC: Gran Canaria.

from cages at both islands (Appendix 3). At La Palma Island, we typically detected significant differences in the percentage of FA with varying distance from the farm; this pattern, however, was minored at Gran Canaria Island, where we exclusively detected significant differences with varying distance from cages in the percentage of $\sum \mathrm{n}-3 / \sum \mathrm{n}-6$ ratio (Figure 7.13 and 7.14 ), muscle total lipid (Figure 7.1), OA from muscle (Figure 7.3) and EPA from muscle (Figure 7.9). A posteriori SNK tests demonstrated that crude lipid from individuals captured at La Palma Island, including both muscle (Figure 7.1) and liver (Figure 7.2) tissues, had significantly larger values in samples coming from 'cages' than 'far away' from cages; 'Near' samples did not differ from 'far away' samples for muscle tissue (Figure 7.1). At La Palma Island, the concentration of OA was significantly higher in samples from 'cages' than 'near' cages' or 'far away', for both muscle (Figure 7.3) and liver (Figure 7.4) samples. Cultured ('cages') European sea bass from La Palma had significantly higher LA (Figure 7.5 and 7.6) and ALA (Figure 7.7 and 7.8) than 'near' and 'far away' samples, for both muscle and liver; fish from 'near' and 'far away' distances did not show significant differences. The percentage of EPA in muscle was larger at 'cages' relative to 'near' and 'far away' samples at Gran Canaria 
(Figure 7.9); at La Palma, however, there was no difference between 'cages' and 'far away' samples (Figure 7.9). The percentage of EPA in liver tissue (Figure 7.10) differed between 'near cages' and 'far away' samples collected from La Palma. $\Sigma \mathrm{n}-9$ and $\Sigma$ Monounsatured FAs from La Palma followed the same pattern: significantly larger values for cultured fish than 'far away', for both muscle (Figure 7.15 and 7.17 , respectively) and liver (Figure 7.16 and 7.18 , respectively) tissue samples.

In contrast, several FAs showed an overall increase in their concentration with distance away from cages. For example, ARA showed higher values in 'far away' than 'cages' and 'near' samples, for both muscle (Figure 7.19) and liver (Figure 7.20) for La Palma, and exclusively for muscle tissue at Gran Canaria (Figure 7.19). At La Palma, the percentage of DHA was significantly higher in 'far away' and 'near' samples than cultured fish ('cages') for muscle samples (Figure 7.11). For liver samples (Figure 7.12), however, there was no difference between 'near' and 'cages'. The concentration of $\sum \mathrm{n}-3$ FAs from La Palma, for both muscle (Figure 7.21) and liver (Figure 7.22), were larger in 'far away' than 'cages' samples. At Gran Canaria, we detected a larger concentration of $\Sigma \mathrm{n}-3$ FAS for muscle samples at 'cages' (Figure 7.21). No difference in the level of PA was registered between 'cages' and 'far away' samples from both islands, for both muscle (Figure 7.23) and liver (Figure 7.24). The $\sum \mathrm{n}-3 / \Sigma \mathrm{n}-6$ ratio and satured FAs from La Palma, for both muscle (Figure 7.13 and 7.25, respectively) and liver (Figure 7.14 and 7.26, respectively), were significant higher from 'near' and 'far away' than 'cages' samples.

Finally, it is worth noting that the percentage of all FAs of cultured fish (i.e. 'cages') differed between islands (Figure 7, Appendix 3), except the fat percentage, DHA, satured, ARA and PA in muscle tissue, and monounsatured, $\Sigma \mathrm{n}-9$, satured, OA and PA in liver tissue.

\section{Discussion}

Populations of European sea bass in the studied islands are related to aquaculture escapes $[12,16]$. Our results agree with this idea, because European sea bass density over time was much higher adjacent to the sea-cage fish farm at Tazacorte, as also demonstrated by Toledo-Guedes et al. [35], than at the other locations, where most fish disappear through time after the massive release. Moreover, the size class distribution of European sea bass from La Palma clearly indicated that the majority of individuals are aquaculture escapees, as also indicated by ToledoGuedes et al. $[13,35]$ for the same escape event. The European sea bass may reach any location around the islands perimeter after a massive escape, showing therefore a great capacity of dispersion as proposed by previous studies [13,16,35-37]. Small, chronic, escapes, however, have not caused a high dispersion of escapees; escaped fish are typically located around cages or in the near coast $[12,16,38]$.

Over time, escaped fish tend to approach shallow waters $[13,16,18,35,37]$. Despite Toledo-Guedes et al. [12] showed a preference by the European sea bass for bottoms covered by boulders on shallow waters, our study demonstrated that escaped European sea bass prefers breakwaters; in particular, higher European sea bass densities were observed in those locations (Tazacorte and Santa Cruz) where breakwater do exist. In this sense, Santa Cruz was the second location with a higher density of fish, in spite of being far away from the escape point (Figure 1). This result contrasts with those observations reported by Toledo-Guedes et al. [35], which demonstrated lower densities in the east face of the island (contrary to the escape location) and so a clear correlation between the distance from the fish farm and European sea bass density. It is noteworthy that this result was despite our sampling and that performed by Toledo-Guedes et al. [13,35] were carried out within a similar temporal window.

Previous studies have concluded that escaped European sea bass is able to exploit natural resources in the Canary Islands $[12,16,36]$. The principal preys identified in all of these studies are common on subtidal bottoms of the Canary Islands. We corroborated this idea, showing an overlap with the diet indicated by Toledo-Guedes et al. for the same escape event, who highlighted Percnon gibessi as the principal prey. However, these authors did not found Rhynchocinetes $s p$ as a relevant diet constituent of escaped fish, although much of escaped fish were caught practically in the same locations and time. These differences could be due to variations in sample size $[11,13,41]$ and, of course, the somehow opportunistic feeding behavior of the European sea bass [10]. Nonetheless, our overall diet results agree with previous studies $[15,39]$ that showed crustacean decapods and osteichthyes as the principal prey of wild European sea bass.

Toledo-Guedes et al. [13] showed that the diet of fishes from massive escape events typically differs as a result of the 'time at liberty'. Previous studies $[13,40]$ highlighted that these differences in escaped fish diet could reflect a 'hunting learning' period, i.e. recent escapees predate mainly over crustaceans that are less mobile and 'more time escaped fish' predate over fish. Lorenzen et al. [7] concluded that there are critical uncertainties on the effects of different domestication strategies on the fitness of cultured fish in the wild. We observed that diets of escaped European sea bass differed between La Palma and Gran Canaria; Percnon gibessi was the main prey for escapees from $\mathrm{La}$ Palma and osteichthyes for Gran Canaria. However, in the light of FA results, 'more time escaped fish' (those from La Palma) mainly fed over crustaceans, while recently escaped fish (those from Gran Canaria) principally fed over fish. These preys are common in both islands, so prey availability does not seem to be the cause of these differences. In any case, we may overestimate this issue, since we have not analyzed a high number of stomachs from Gran Canaria, due to difficulties to find escaped fish.

Escaped European sea bass diet includes a high percentage of inorganic items $[12,16]$. Carrillo and Castillo and Toledo-Guedes et al. [12] showed a mean $82.63 \%$ and $50 \%$ (respectively) of stomach vacuity, proving evidence of a low adaptation to wild conditions of escaped individuals. Yet, we recorded a mean stomach vacuity of $25.97 \%$, suggesting a high variability of this parameter. In any case, inorganic matter (sand and plastics) was the third main item in the stomachs of escaped European sea bass in our study, highlighting the difficulties of escaped fish to wild feeding conditions. Toledo-Guedes et al. [13] reported a similar value for long-term escaped fish (33.9\% of vacuity), while the value was lower for recently escaped fish ( $12.5 \%$ vacuity); as a result, this contradicts the previous idea and suggest that the European sea bass is able to actively exploit available resources in natural habitats.

European sea bass requires low salinities $(<35 \%)$ in its natural habitat to trigger gametogenesis; in turn, the last phase of gonadal development require a $c a .35 \%$ of salinity and, concurrently, larval survival increases at low salinities. Spawning optimal thermal range is $13-15^{\circ} \mathrm{C}$ [41]. Recruitment is typical in estuarine habitats across its distribution range $[10,15,42]$. During eggs incubation, the optimal temperature range is between $13^{\circ}-17^{\circ} \mathrm{C}$ [43-45] and larval development lasts 46 days at $16.5^{\circ} \mathrm{C}$ [46]. European sea bass first maturation is reached at a range of length between $23-46 \mathrm{~cm}$ [47] and the reproduction often occurs between December-March [15,48-50].www.fishbase.org In our study, only a very low number of individuals, including both males and females, showed mature gonads; this contrasts with a larger number 

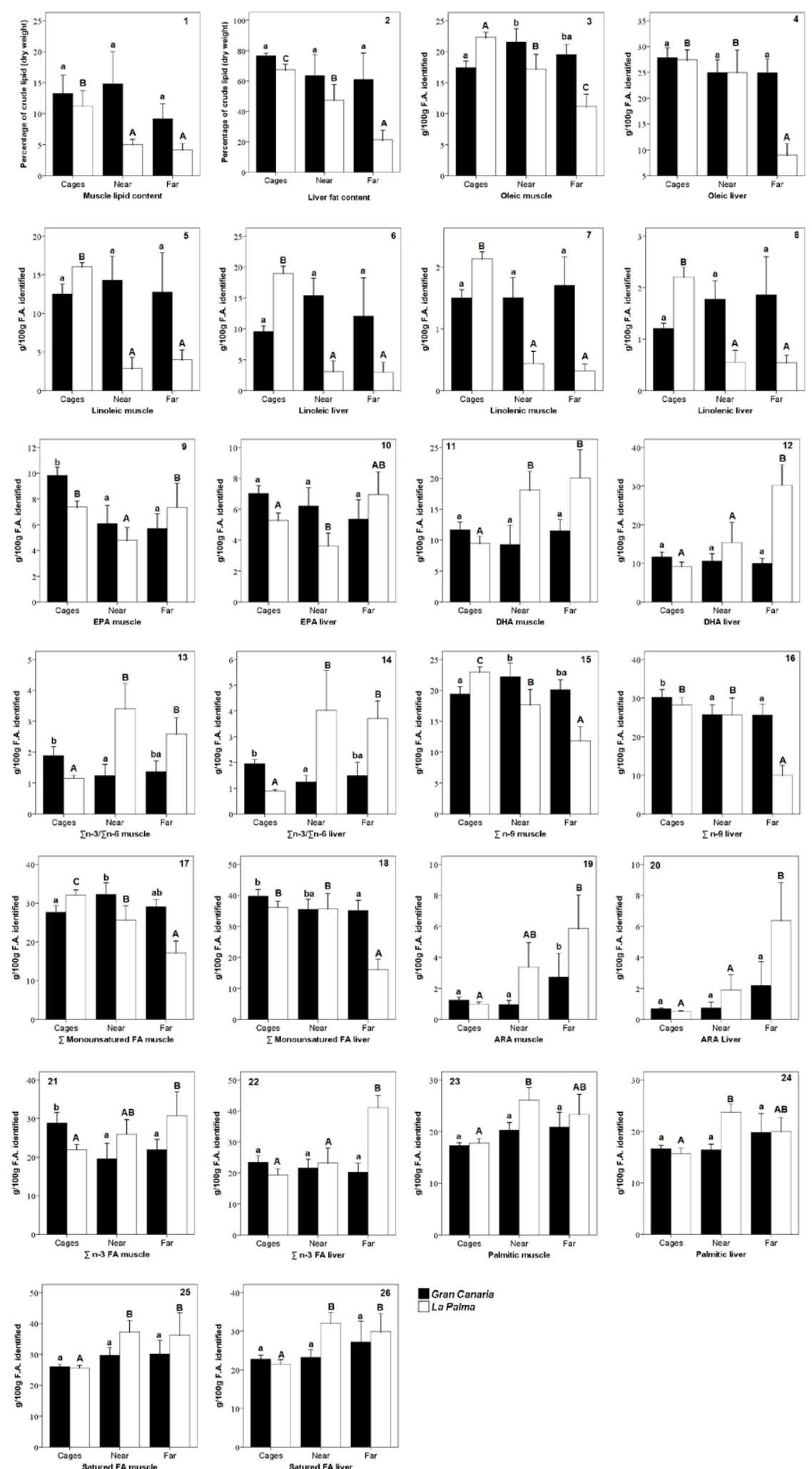

Gran Canaria

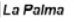

Figure 7: Percentage of lipid content and fatty acids in muscle and liver of escaped sea bass, Dicentrarchuslabrax,from 'cages', 'near' (<10 km away from the cages) and 'far' (>10 km away from the cages). Alphabetic superscripts denote significant differences among distances away from farms. 1)muscle lipid content; 2) liver fat content; 3) muscle oleic acid $(18 \cdot 2 n-9) ; 4)$ liver oleic acid $(18 \cdot 2 n-9) ; 5)$ muscle linoleic acid (18.2n-6); 6) liver linoleic acid (18:2n-6); 7 ) muscle linolenic acid $(18: 3 n-3)$; 8) liver linolenic acid $(18: 3 n-3) ; 9)$ muscle eicosapentaenoic acid $(20: 5 n-3)$; 10) liver eicosapentaenoic acid $(20: 5 n-3) ; 11)$; muscle docosahexaenoic acid (22:6n-3); 12) liver docosahexaenoic acid (22:6n-3); 13) muscle ratio $n-3 / n-6$; 14) liver ratio $n-3 / n-6 ; 15)$ muscle $\sum n-9$ FA; 16) liver $\sum$ n-9 FA; 17) muscle $\sum$ monounsatured $F A ; 18)$ liver $\sum$ monounsatured $\left.F A ; 19\right)$ muscle arachidonic acid $\left.(20: 4 n-6) ; 20\right)$ liver arachidonic acid (20:4n-6); 21) muscle $\left.\sum n-3 F A ; 22\right)$ liver $\sum n-3$ $\mathrm{FA} ; 23)$ muscle palmitic acid $(16: 0) ; 24)$ liver palmitic acid $(16: 0) ; 25)$ muscle $\sum$ satured $\left.F A ; 26\right)$ liver $\sum$ satured FA. 
of mature gonads found by Toledo-Guedes et al. [12]. However, both studies have not found evidence of reproduction. This is noteworthy, because individuals were in their sexual maturity period. In addition, only one male at a spawning state was observed. This could be because the range of temperature and salinity necessary for gonadal development [39] is not present in the studied islands (including higher temperatures). Even if the European sea bass would spawn, neither incubation of eggs conditions, nor term-haline conditions for larval development [44-46], are present in the Canary Islands. The sex ratio (1:1) was, moreover, not optimal (4:1 according to Arias [11]) and no juvenile European sea bass had been reported $[12,13,16]$. Therefore, there is no evidence of European sea bass reproduction at La Palma and Gran Canaria islands, as similarly concluded by Toledo-Guedes et al. [12] and Carrillo and Castillo [16]. In any case, further and more specific studies would be necessary in order to know escaped European sea bass capacity of reproduction in Canary Islands.

After the mass escape event, the number of European sea bass decreased through time, almost disappearing, providing evidence that no more escape events occurred at La Palma Island. A similar conclusion was highlighted by Toledo-Guedes et al. [12,35]. This decrease is principally due to a high fishing pressure, failure to adapt (starvation, deformities) and predation by large-sized fish (e.g. Seriola sp, Sphyraena viridensis, Pomatomus saltatrix) [4,8,12,35,37,38,51-53]. Nevertheless, Arechavala-López et al. [8] showed low recapture rates by local fishermen on European sea bass inform the Mediterranean Sea (including both recreational and professional captures). As previous studies, we also recognize fishing pressure as a significant driver of the progressive decay in fish abundances through time. About 63 tons of escaped European sea bass were fished by this professional (artisanal) fleet during the study period in La Palma ('Consejería de Agricultura y Pesca del Gobierno de Canarias', pers. comm.) and recreational fishermen captures have been reported as larger than 100 fish, or 100 $\mathrm{kg}$, per angler in just one day in the study region [37]. If we assume that recreational captures were larger than those performed by professional fishermen, the overall capture was far from reaching $c a .400$ tons of escaped European sea bass. We then hypothesize that remaining fish were predated or non-adapted. Moreover, the great decrease occurred during October, matching the arrival at coastal areas of migratory, large-sized, predators (tuna, yellowtails, Sphyraena viridensis, dolphins and sharks) [54]. Beside this, it is plausible that escaped European sea bass may compete with native species, such as Dicentrarchus punctatus, juveniles of Sphyraena viridensis, Synodus sp., Serranus sp., which have a similar ecological niche and feeding habits, as concluded by González-Lorenzo et al. [36], Toledo-Guedes et al. [12] and Tavares and González .

In the light of overall FA results, it seems clear that escaped fish from Gran Canaria were recently escaped, because no difference existed with varying distance from aquaculture cages. In particular, the 18:C FAs would tend to be eliminated or washed-out progressively from the muscle, as soon as those animals finish to feed aquafeeds and begin to feed on wild prey $[55,56]$. This emphasizes the rapid dispersion that European sea bass presents after an escape event as we observed at La Palma by means of visual census. FA profiles of escapees changes over time after an escape by wash-out $[27,53]$ so it seems clear that escaped European sea bass at La Palma have been more time escaped than at Gran Canaria. Our initial hypothesis aimed to relate distance with time (more distance, more time to disperse, more wash out), but we somehow failed to detect this, mainly because this species has a quick dispersion behavior. The FA composition of muscular tissue is often related to dietary FA composition [57], so some FAs can be used as bioindicators of escaped fish [23,25,26,58-61]. Normally, reared European sea bass present higher proportions of OA and LA and lower proportions of PA, ARA, EPA, and DHA than wild European sea bass $[23,27,62]$. Additionally, percentages of total saturated, as well as the n-3/n-6 ratio, are higher in wild than cultured European sea bass $[23,62]$; these results match the outcomes of this study. FA composition, however, may not be reliable biomarkers of aquaculture activities since other human activities, including discharges of urban waters, may induce similar changes [53], directly by feeding or due to the relatively high conservation of FA composition throughout the food web [23]. This is particularly relevant for European sea bass, as a result of its quick dispersion behaviour. We also observed differences in the profile of FAs between cultured fish from Gran Canaria and La Palma; this is a consequence of continuous changes in aquafeeds formulae that depends on the ingredients availability and fluctuating market prices [63]. DHA, OA and LA seem to be selectively retained in European sea bass muscle [57]. When fish that has been fed with vegetable oil containing diets is subjected to a period of fish oil re-feeding, the amount of $18^{\circ} \mathrm{C}$ FAs (particularly LA in those fish fed previously with soybean oil containing diet) remains higher and EPA lowers [57]

To determine if a FA is a good aquaculture biomarker, it would be necessary to perform a study at the same region, where the FA composition should be in similar from both culture and escaped fish and distinct from wild fish. In the present study, however, there was no wild fish, so we were able to exclusively assess if FA composition changed with varying distance from farms. Contrary to FernándezJover [23], FA profile cannot be used as biomarkers, because there were significant differences between distance groups ('cages'-'near'-'far') in this study. Moreover there is an inconsistency for FAs highlighted among several studies $[27,53,61,64,65]$, so the usefulness of FAs as biomarkers for escaped fish is doubtful. We found different FAs than those proposed by Arechavala-López et al. [66] (i.e. LA and ARA) as possible biomarkers. The current study could suggests PA (liver) and EPA (both at liver and muscle) as the candidates as possible biomarkers, because these FAs were not different with varying proximity from the farms; however further studies are necessary to confirm its reliability. This matches the result showed by Montero et al. [57], where EPA values did not become to control diet (fish oil) after a re-feeding period in the laboratory. In the Canary Islands, Ramírez et al. [53] concluded that ALA is a possible aquaculture biomarker for bogue, Boops boops, a zooplanktivorous and opportunistic fish that aggregates around sea-cage fish farms in the Canary Island and the Mediterranean; this is because samples taken around sewage discharge points did not increase the ALA percentage. However, this study demonstrated that ALA cannot be used as a biomarker for escaped European sea bass. FAs could be used to identify escaped fish when matching similar FA profiles from cultured fish. However, if FA profiles do not match those of cultured fish, it is impossible to work out whether a fish has been born in the wild or, alternatively, is an old escapee that has progressively suffer a wash-out.

In summary, despite escaped fish being able to exploit natural resources, the density of escapees decreased through time. Those fish able to adapt and use natural resources altered their FA profiles in comparison to cultured fish, denoting the poor usefulness of FA profile as a good bio-indicator, limiting their potential to a very short period of time after escape events.

\section{Acknowledgement}

Authors would like to thank María López Ruano for her help to produce this document. Our thanks also go to Tamia Brito, manager of La Palma Marine 
Citation: Ramírez B, Ortega L, Montero D, Tuya F, Haroun R (2015) Monitoring a Massive Escape of European Sea Bass (Dicentrarchus Labrax) at an Oceanic Island: Potential Species Establishment. J Aquac Res Development 6: 339. doi:10.4172/2155-9546.1000339

Page 8 of 9

Protected Area. The staff at Acuipalma S.L., for their collaboration. David Jiménez Alvarado and Yamilet Cárdenes are acknowledged for their assistance during field sampling. This work was funded by Prevent Escape project $\left(n^{\circ} 226885\right)$

\section{References}

1. CBD (Secretariat of the Convention on Biological Diversity) (2004) Solutions for sustainable mariculture avoiding the adverse effects of mariculture on biological diversity.

2. Molina L, Vergara J (2005) Impacto ambiental de jaulas flotantes: estado actual de conocimientos y conclusiones prácticas. Boletín del Instituto Español de Oceanografía 21: 75-81.

3. Naylor R, Hindar K, Fleming IA, Goldburg R, Williams S, et al. (2005) Fugitive salmon: assessing the risks of escaped fish romnet-pen aquaculture. Bioscience 55: 427-437.

4. Vergara JM, Haroun R, González MN, Molina L, Briz MO, et al. (2005) Environmental Impact Assessment of Cage Aquaculture in Canarias Pesquera.

5. Jensen O, Dempser T, Thorstad EB, Uglem I, Fredheim A (2010) Escapes of fish from Norwegian sea-cage aquaculture: causes, consequences and preventions. Aquaculture Environmental Interactions 1: 71-83.

6. Grigorakis K, Rigos G (2011) Aquaculture effects on environmental and public welfare; The case of Mediterranean mariculture. Chemosphere 85: 899-919.

7. Lorenzen K, Mangel M (2012) Cultured fish: integrative biology and management of domestication and interactions with wild fish. Biological Reviews of the Cambridge Philosophical Society 87: 639-660.

8. Arechavala-Lopez P, Izquierdo-Gómez D, Sánchez-Jerez P, Bayle-Sempere J (2014) Simulating escapes of farmed European sea bass from Mediterranean open sea-cages: low recaptures by local fishermen. Journal of Applied Ichthyology 30: 185-188.

9. Tortonese E (1986) Moronidae.

10. Laffaille P, Lefeuvre JC, Schricke M, Feunteun E (2001) Feeding ecology of 0 -group sea bass, Dicentrarchus labrax, in salt marshes of Mont Saint Michel Bay (France). Estuaries and Coasts 24: 116-125.

11. Leitao F, Santos M, Erzini K, Monteiro C (2008) The effect of predation on artificial reef juvenile demersal fish species. Marine Biology 153: 1233-1244.

12. Toledo-Guedes K, Sánchez-Jerez P, González-Lorenzo G, Brito A (2009) Detecting the degree of establishment of a non-indigenous species in coastal ecosystems: sea bass Dicentrarchus labrax escapes from sea cages in Canary Islands (Northeastern Central Atlantic). Hydrobiologia 623: 203-212.

13. Toledo-Guedes-Guedes K, Sánchez-Jerez P, Benjumea M, Brito A (2014) Farming-up coastal fish assemblages through a massive aquaculture escape event. Marine Environmental Research 98: 86-95.

14. Kennedy M, Fitzmaurice $P$ (1972) The biology of the bass, Dicentrarchus labrax (Linné 1758), in Irish waters. Journal of the Marine Biological Association of the United Kingdom 3: 39-68.

15. Arias A (1980) Growth, diet and reproduction of the golden (Sparusaurata L.) and sea bass (Dicentrarchus labrax L.) in the estuaries. Fisheries Research 44: 59-83.

16. Carrillo J, Castillo R (2001) Estudio del Impacto producido por la introducción de las lubinas (Dicentrarchus labrax Linnaeus, 1758) y doradas (Sparus aurata, Linnaeus, 1758), escapadas de los cultivos en jaulas flotantes, en el ecosistema marino litoral de Gran Canaria. Informe inédito. Gran Canaria: 2001.72 pp. Viceconsejería de Pesca del Gobierno de Canarias.

17. Carrillo M, Zanuy S, Blazquez M, Ramos J, Piferrer F, et al. (1995) Sex control and diploid manipulation in European sea bass.

18. Dunn RJK, Welsh DT, Teasdale PR, Lee SY, Lemckert CJ, et al. (2008) Investigating the distribution and sources of organic matter in surface sediment of Coombabah Lake (Australia) using elemental, isotopic and fatty acid biomarkers. Continental Shelf Research 28: 2535-2549.

19. Hu J, Zhang G, Li K, Peng P, Chivas AR González-Lorenzo (2008) Increased eutrophication offshore Hong Kong, China during the past 75 years: evidence from high-resolution sedimentary records. Marine Chemistry 110: 7-17.

20. Maazouzi C, Masson G, Izquierdo MS, Pihan JC (2008) Chronic coppe exposure and fatty acid composition of the amphipod Dikerogammarus villosus: results from a field study. Environment Pollution 156: 221-226.
21. Izquierdo MS, Koven W (2011) Lipids.

22. Tacon AGJ, Metian M (2008) Global overview on the use of fish meal and fish oil in industrially compounded aquafeeds: trends and future prospects. Aquaculture 285: 146-158.

23. Albert GJT, Marc Metianb (2011) Global overview on the use of fish meal and fish oil in industrially compounded aquafeeds: Trends and future prospects. Aquaculture Environment Interactions 285: 146-158.

24. Skog T, Hylland K, Torstensen BE, Berntssen M (2003) Salmon farming affects the fatty acid composition and taste of wild saithe Pollachius virens $L$. Aquaculture Research 34: 999-1007.

25. Fernández-Jover D, Lopez-Jimenez J, Sanchez-Jerez P, Bayle-Sempere J Gimenez-Casalduero F, et al. (2007) Changes in body condition and fatty acid composition of wild Mediterranean horse mackerel (Trachurus mediterraneus, Steindachner, 1868) associated to sea cage fish farms. Mar Environt Res 63 : 1-18.

26. Rueda FM, Hernández MD, Egea MA, Aguado F, García B, et al. (2001) Differences in tissue fatty acid composition between reared and wild sharpsnout sea bream, Diplodus puntazzo (Cetti, 1777). British Journal of Nutrition 86 : 617-622.

27. Arechavala-López P, Fernández-Jover D, Black K, Ladoukakis E, BayleSempere J, et al. (2013) Differentiating the wild or farmed origin of Mediterranean fish: a review of tools for sea bream and European sea bass. Reviews in Aquaculture 5: 137-157.

28. Tuya F, Boyra A, Sánchez-Jerez P, Haroun RJ, Barberá C (2004) Relationships between rocky-reef fish assemblages, the sea urchin Diadema antillarum and macroalgae throughout the Canarian Archipelago. Marine Ecology Progress Series 278: 157-169.

29. Arias A (1979) Experimental Biology and cultivation of the golden Sparus aurata $L$., and sea bass Dicentrarchus labrax $L$.

30. AOAC. Association of Official Analytical Chemists (2000) Official Methods of Analysis.

31. Folch J, Lees M, Sloane-Stanley GH (1957) A simple method for the isolation and purification of total lipids from animal tissues. J Biol Chem 226: 497-509.

32. Christie W (1982) Lipid Analysis.

33. Izquierdo MS, Watanabe T, Takeuchi T, Arakawa T, Kitajima C (1990) Optimum EFAlevels in Artemia to meet the EFA requirements of red sea bream (Pagrus major).

34. Underwood AJ, (1997) Experiments in ecology. Their logical design and interpretation.Cambridge University Press, UK

35. Toledo-Guedes K, Sánchez-Jerez P, Brito A (2014) Influence of a masive aquaculture escape event on artisanal fisheries. Fisheries Management and Ecology 21: 113-121.

36. González-Lorenzo G, Brito A, Barquín J (2005) Impacts of fish escapes cage mariculture in the Canaries. Vieraea 33: 449-454.

37. Tavares D, González N (2009) Characterization of events exhaust Sparus aurata and Dicentrarchus labrax in Gran Canaria by interviewing anglers.

38. Arechavala-Lopez P, Uglem I, Fernández-Jover D, Bayle-Sempere J, SánchezJerez P (2011) Immediate post-escape behaviour of farmed European sea bass (Dicentrarchus labrax) in the Mediterranean Sea. Journal of Appl Ichthyol 27: $1375-1378$

39. FAO (Food and Agriculture Organisation) (2012) Fish finder

40. Arechavala-Lopez P, Uglem I, Fernandez-Jover D, Bayle-Sempere JT, Sanchez-Jerez P (2012) Post-escape dispersion of farmed seabream (Sparus aurata L.) and recaptures by local fisheries in the Western Mediterranean Sea. Fish Res 121-122: 126-135

41. Moretti A, Pedini G, Fernandez-Criado M, Cittolin G, Guidastri R (1999) Hatchery production procedures. In: Manual on hatchery production of seabass and gilthead seabream (vol 1). FAO, Rome, Italy.

42. Serrano L (1989) Age, Growth and sexuality of sea bass, Dicentrarchus labrax (Linnaeus758) (Perciformes, Moronidae) from Aveiro lagoon, Portugal. Scientia Marina 53: 121-126.

43. Dufour V, Cantou M, Lecomte F (2009) Identification of sea bass (Dicentrarchus labrax) nursery areas in the north-western Mediterranean Sea. Journal of the 
Citation: Ramírez B, Ortega L, Montero D, Tuya F, Haroun R (2015) Monitoring a Massive Escape of European Sea Bass (Dicentrarchus Labrax) at an Oceanic Island: Potential Species Establishment. J Aquac Res Development 6: 339. doi:10.4172/2155-9546.1000339

Marine Biological Association of the United Kingdom 89: 1367-1374.

44. Devauchelle N, Coves D (1988) The characteristic of European sea bass (Dicentrarchuslabrax) eggs: descripction, biochemical composition and hatching performances. Aquatic Living Resources 1: 223-230.

45. Saka S, Firat K, Kamaci H (2001) The development of European sea bass (Dicentrarchuslabrax L., 1758) eggs in relation to temperature. Turkish Journal of Veterinary and Animal Sciences 25: 139-147.

46. Houde E, Zastrow C (1993) Ecosystem and taxon-specific dynamic and energetics properties of fish larvae assemblages. Bulletin of Marine Sciences53: 290-335

47. Froese R, Pauly D (2006) Fish base.

48. Do Chi T, Hoai T (1971) Croissance différentielle of Dicentrarchus labrax (Linnaeus 1758).

49. Barnabé G (1976) Contribution to the connaissance of biologie du loup Dicentrarchus labrax (L.) (Poisson Serranidae).

50. González A (2003) Aromatase cytochrome P450 activity in the sea bass (Dicentrarchus labrax).

51. Sanchez-Jerez P, Fernandez-Jover D, Bayle-Sempere J, Valle C, Dempster T, et al. (2008) Interactions between blue fish (Pomatomus saltatrix.) and coastal sea-cage farms in the Mediterranean Sea. Aquaculture 282: 61-67.

52. Arechavala-Lopez P, Uglem I, Sanchez-Jerez P, Fernandez-Jover D, BayleSempere JT, et al. (2010) Movements of grey mullets (Liza aurataand Chelonlabrosus) associated with coastal fish farms in the western Mediterranean Sea. Aquaculture Environment Interactions 1: 127-136.

53. Ramírez B, Montero D, Izquierdo M, Haroun R (2013) Aquafeed imprint on bogue (Boopsboops) populations and the value of fatty acids as indicators of aquaculture-ecosystem interaction: Are we using them properly? Aquaculture 414-415: 294-302.

54. Bas C, Castro J, Hernández-Gracía V, Lorenzo JM, Moreno T, et al. (1995) Fishing in the Canary Islands and areas of influence.

55. Torstensen BE, Froyland L, Ornsrud R, Lie O (2004) Tailoring of a cardio protective muscle fatty acid composition of Atlantic salmon (Salmosalar) fed vegetable oils. Food Chemistry 87: 567-580.

56. Izquierdo MS, Montero D, Robaina LE, Caballero MJ, Rosenlund G, et al.
(2005) Alteration in fillet fatty acid profile and flesh quality in gilthead sea bream (Sparusaurata) fed vegetable oils for a long period. Recovery of fatty acid profiles by fish oil feeding. Aquaculture 250: 431-44.

57. Montero D, Robaina L, Caballero MJ, Gines R, Izquierdo MS (2005) Growth feed utilization and flesh quality of European seabass (Dicentrarchuslabrax) fed diets containing vegetable oils: a time-course study on the effect of a refeeding period with a $100 \%$ fish oil diet. Aquaculture 248: 121-134.

58. Bell JG, Henderson RJ, Tocher DR, McGhee F, Dick JR, et al. (2002) Substituting fish oil with crude palm oil in the diet of Atlantic salmon (Salmosalar) affects muscle fatty acid composition and hepatic fatty acid metabolism. Journal of Nutrition 132: 222-230.

59. Blanchet C, Lucas M, Julien P, Morin R, Gingras S, et al. (2005) Fatty acid composition of wild and farmed Atlantic salmon (Salmosalar) and rainbow trout (Oncorhynchusmykiss). Lipids 40: 529-531.

60. Megdal PA, Craft NA, Handelman GJ (2009) A simplified method to distinguish farmed (Salmosalar) from wild salmon: Fatty acid ratios versus astaxanthin chiral isomers. Lipids 44: 569-576.

61. Mnari A, Bouhlel I, Chraief I, Hammami M, Romdhane MS, et al. (2007) Fatty acids in muscles and liver of Tunisian wild and farmed gilthead sea bream Sparusaurata. Food Chemistry 100: 1393-1397.

62. Alasalvar C, Taylor K, Zubcov E, Shahidi F, Alexis M (2002) Differentiation of cultured and wild sea bass (Dicentrarchuslabrax): total lipid content, fatty acid and trace mineral composition. Food Chem. 79: 145-150.

63. Gunstone FD (2010) The world's oil and fats.

64. Grigorakis K, Alexis MN, Taylor KD, Hole M (2002) Comparison of wild and cultured gilthead sea bream (Sparusaurata); composition, appearance and seasonal variations. International Journal of Food Science and Technology 37: 477-484.

65. Arechavala-Lopez P, Sanchez-Jerez P, Bayle-Semper J, Fernandez-Jover D Martinez-Rubio L, et al. (2011) Direct interaction between wild fish aggregations at fish farms and fisheries activity at fishing grounds: a case study with Boops boops. Aquaculture Research 42: 996-1010.

66. Arechavala-Lopez P, Sánchez-Jerez P, Bayle-Sempere J, Uglem I, Mladineo I (2013) Reared fish, farmed escapees and wild fish stocks - a triangle of pathogen transmission of concern to Mediterranean aquaculture management. Aquaculture Environment Interactions 3: 153-161. 